\title{
Signing off... As Editor in Chief
}

\author{
Suvarna Khadilkar ${ }^{1}$
}

Received: 11 November 2020 / Accepted: 13 November 2020 / Published online: 24 November 2020

(c) Federation of Obstetric \& Gynecological Societies of India 2020

\begin{abstract}
I complete my tenure as editor in chief in January 2021, and here I bring to you the last editorial of my tenure. I have enjoyed every moment of this long association with the journal. I have done my best to improve the quality of this journal in terms of readership, citations, visibility, academic recognition, promoting good quality research and publications. Many new changes were brought in during my tenure including the publishing e-book of our journal which has furthered the go green initiative of FOGSI.
\end{abstract}

Keywords Editor in chief $\cdot$ Signing off

I present a brief account of journal functioning and graph of the growth of the journal over last three years before I bid adieu to this prestigious post with a heavy heart.

\section{My Journey so far}

Way back in 1986, I undertook my first research for my thesis on cervical encerclage under guidance of my postgraduate teacher Dr. Jasmine Lopez. That was my first introduction to conducting research and also publishing it in this very prestigious Journal of Obstetrics and Gynecology of India (JOGI) [1]. Back then, I had never imagined that I would be associated with this journal so closely for so many years and one day I would be at the helm of its affairs!

In this last editorial of my tenure, I will love to share some experiences of this journey, starting from an aspiring student, reader, author, proof reader, secretary, manager and

Prof. Suvarna Satish Khadilkar MD DGO FICOG, CIMP, Diploma in Endocrinology (UK) is Editor in Chief of Journal of Obstetrics and Gynecology of India, and Treasurer, FOGSI; she is Professor and Head, and Consultant Gyne-Endocrinologist, Bombay Hospital and Medical Research Centre, Mumbai, Former Professor and Head, Dept of Ob-Gyn, RCSM, Government Medical College, Maharashtra and Associate Professor and Unit Chief Grant Medical College and Cama and Albless Hospital, Mumbai.

Suvarna Khadilkar

suvarnakhadilkar2@gmail.com

1 Bombay Hospital and Medical Research Centre, Mumbai, India editors to reach the final destination of the post of editor in chief!

It was in 1998, I was requested to serve JOGI as "Honorary Proof Reader" to which I agreed and started working. Even though I was keen to learn something new, I was a little hesitant, as the title did not sound very attractive and bewilderingly, the letter clearly mentioned that my name would not appear anywhere in the journal.

When I reflect from the position of EIC, let me say very proudly, that it was one of the best decisions of my life. That decision helped pave my way up the ladder and enabled me to complete my tenure as editor in chief successfully. We all know that this post attracts lot of respect and recognition in the academic arena, but hardly did I know then that this was going to be a 22 years long enriching journey!

Those days, the journal was available only as a print copy, and proof reading had to be done on hard copies by the editorial team and assistants. Journal did not have any technical assistance from publishers till as late as 2003. Prints of the proofs had to be delivered physically to editorial and proof reading teams. So perhaps I was chosen as I was working as an associate professor and was available on campus of Cama and Albless hospital, where the JOGI office was located. Later I was selected and appointed as joint assistant secretary of JOGI, which was an ascending post. My consistent and persistent hard work, and of course my passion for writing and editing kept me going. I had great opportunity to work under valuable guidance and leadership of stalwarts like Dr. RD Pandit, Dr. MN Parikh, Dr. Adi Dastur, Dr. CN Purandare, Dr. Gautam Allhabadia and Dr. CV Hegde. Each of these respectable 
editors had unique editorial styles, and I could learn something new from all of them during my tenure of ascending editorial positions on JOGI.

I took additional charge as editor in chief in October 2017 because of early resignation of my predecessor Dr. CV Hegde, due to his serious ill-health. Soon thereafter journal lost this great dedicated editor in chief. It came as a shock, and it was truly very challenging for me as I was already holding the charge of many coveted posts with great responsibilities in many other organizations. Each of these posts was very demanding, and I could offer only $24 \mathrm{~h}$ in a day to serve on all these posts and do justice to all of them. I did not know how to cope up with these unforeseen circumstances. Like always, it was my mentors and teachers Dr. CN Purandare and Dr. KK Deshmukh who instilled in me that huge confidence and advised me to consider these challenging times as opportunities to become stronger and better. I can never be grateful enough to them, and also all the organizations I was working for, for teaching me patience, responsibility, time-management and the importance of upholding values. While I was holding many posts with many responsibilities, playing multiple roles in personal life and on professional front, the primary recipient of my attention since the last few years has been JOGI and its editorial responsibilities. I haven't regretted a single moment that I spent for this journal.

\section{Editorials}

After taking charge as EIC, I soon began the toughest task of writing editorials every two months on contemporary issues. It is this journal which helped me improve my writing and editing skills to bring to you issues with quality articles on time. I thank all my readers, clinicians, well-wishers who sent appreciation notes, from the bottom of my heart. I hope the editorials written by me as well as other articles which were edited by me and my team, changed the way they practiced.

I am extremely happy to share with you all that the accesses of my articles have crossed unprecedented " 40,000 " mark as of November 2020. In my first year, I wrote my editorial series on medical writing and ethical aspects of medical writing [2-7], second year, I chose the editorial series on gyn-endocrinology [8-13], a topic close to my heart, and third year, I had a few guest editorials and some miscellaneous topics of common interest [14-18].

\section{Popularity of the Articles}

From the desk of the editor in chief, one develops a bird's eye view and soon I started understanding how to target and select what is good for the journal. I sincerely thank all of you for making our articles highly popular, and many interesting articles have become the topmost read articles in the history of this journal. Musculoskeletal Disorders and Menopause [9] became the most popular article with the top most full text requests, whereas Thyroid-Stimulating Hormone Values in Pregnancy: Cutoff Controversy Continues? [12] became the most popular article with $13,000+$ accesses, highest ever in the history of JOGI.

The journal published the first ever original largest case control study of impact of Covid-19 infection on pregnancy [19], and within 3 months, it has already attracted 2000 accesses and 2 citations.

The journal has done very well as regards the visibility, reads and citations, but surely there is a lot of scope for improvement. In 2019, out of 382 citable articles 173 articles were cited globally. The articles accesses have significantly improved in last three years. On an average, editorials accesses before 2017 were around 800, whereas last three years this average has increased almost 10 times, i.e., around 4500-12,000. We sincerely hope that we witness a similar increase in the citations in coming years. The quality of the papers being submitted is significantly getting better. But there is a lot of scope to improvise the quality to meet standards of high-impact international journals.

\section{Overview of New Changes}

I would like to give you a quick recap of what new changes were brought in to improvise the quality of the journal during my tenure.

My tenure began with a new look of cover design which was appreciated by many. Reaching out to 37,000 plus members every two months in time had always been a challenge. First time ever, the FOGSI members started receiving the link to the bimonthly issue of the JOGI on their hand-sets, adhering to the proposed date of release of the issue. This movement eliminated many complaints of non-receipt of the print issue to their addresses. We published 18 regular issues and two supplements along with one covid-19 special section.

\section{Types of Articles}

Three new types of articles namely Pictorial Essay, Systematic Reviews/Meta-Analysis, and Invited Debate were introduced. The review articles, besides being invited from reputed authorities, were newly opened to authorship worldwide which gave opportunities to many experts in their respective fields yet unexplored by JOGI. These received a good response from authors and readers. 


\section{Plagiarism Checking and Manuscript Screening}

Journal had witnessed a few complaints regarding plagiarized articles in past. First time ever, the plagiarism checking of all the articles was initiated, which was a landmark in the history of the journal as we could completely eliminate plagiarized articles which significantly improved the originality of the articles submitted to this journal. We also put in place the mechanism for taking due action against any scientific misconduct noticed by the team.

Editorial discussion was introduced for the first time which really enabled detailed editorial scrutiny to improvise the efficiency of processing, and it was possible to know and exchange views of other editors to select articles worthy of consideration for further processing. Pre-acceptance checking was introduced for articles to be accepted to eliminate technical errors and further improve the quality.

It was indeed a proud moment for our journal when it was taken up by Maharashtra university of health sciences (MUHS), to include in their "must read section" of syllabus of MS obstetrics and gynecology course. This was one of the important milestones in endorsing academic growth of the journal.

\section{Search Engine Optimization of JOGI Website}

Google search of our archived articles, right from 1950 to 2003 as well as all the past issues right from 2003 to date is optimised, they are now easily searchable, and website is made much user-friendly now. There were many hurdles in accessing the Indian research data. JOGI is number one journal in field of obstetrics and gynecology in India, hence has largest data base. With this search engine optimization, any author/ researcher from any corner of the world can browse through the Indian data very easily. Our website hosts the abstracts of all the articles published so far and full texts are also freely accessible for all members. They need to $\log$ on to our journal website https://www.jogi.co.in/ and do this optimized search. Now on, it will be very easy to search and cite the work published in our journal. This website gives direct link to springer site https://www.springer.com/journal/13224 where the full text can be accessed.

We have now given links to newly developed videos of tutorials on how to $\log$ in, search and cite the work published in our journal. This enables users to easily navigate through our journal website.

\section{Covid-19 and Journal Functioning}

I feel very happy that first ever e-PICSEP [Program for inculcating culture of scientific enquiry and pursuit] workshop was conducted in Vizag on 25 July during lockdown. After initiation, they have continued because of the covid19 times. These workshops now attract a huge attendance compared to physical PICSEP programs which were held in past. I feel very proud that I was associated with JOGI's workshops on research methodology right from its inception since many years.

My all-time dream of going green was realized into a reality in Covid-19 times. We released first ever ecofriendly and economic e-book of our journal in March-April, issue 2 of 2020 and will be released every two months henceforth. All the issues will be available on our website in future even after the printing resumes normally.

Our editorial board meetings and journal committee and managing committee meetings were conducted as per schedule despite COVID restrictions and lockdowns. First ever virtual board meeting and virtual journal committee meetings happened during lockdown and continued thereafter.

The editorial manager witnessed huge load of submissions of scientific papers, and it was a tough task handling the increased load almost twice than usual submissions.

Journal is also judged by their peer reviewer's quality. Another major endeavor is undertaken to initiate a training course for the editors and peer reviewers. These courses are being established and are almost ready to be implemented in coming few days. I believe it will go a long way to take a big leap in improving the quality of the articles being processed and published.

\section{Constitutional Reforms}

Constructive changes in constitution of FOGSI/JOGI were done to promote talents from all over India.

The title of EIC was first time coined which is generally a norm. Editorial positions opened up to all India candidates. Selection process was first time made transparent and performance based.

\section{Gratitude}

I am indebted to my advisers, editorial board members, international and national advisors, reviewers, journal committee members, executive editor of springer and the entire springer team and office staff for being of great help to editorial development and improvisation of quality of this journal. 
I sincerely look forward to continuing to interact with all of you all dear readers, authors, reviewers, deputy and associate editors over the coming years, and I wish to see JOGI continuing to grow and publish novel science, ultimate aim of which is to improve the health of women of India and across the globe.

I bid adieu to the EIC post, but not to the journal! While this journey comes to an end in terms of posts and privileges, I shall always be available for the journal's cause, the lovely memories will stay with me forever and I shall certainly relish these memories. I wish the incoming editorial team all the very best, and I am sure they will continue to strive for excellence, aim to achieve greater heights to meet with the international standards.

\section{Signing Off....}

\section{References}

1. Khadilkar SS, Lopez JA, Purandare CN, Deshmukh KK. Evaluation of pregnancy outcome following encerclage operation using USG \& scoring system. J Obstet Gynecol India 1988;1:18-21. https://www.jogi.co.in/articles/view.php?id=NTM5Nw

2. Khadilkar S. Change of guard. J Obstet Gynecol India. 2018a;68:1-2. https://doi.org/10.1007/s13224-017-1088-y.

3. Khadilkar SS. Journey of a research article. J Obstet Gynecol India. 2018b;68:75-6. https://doi.org/10.1007/s 1322 4-018-1110-z.

4. Khadilkar SS. The Art and craft of making a draft: writing a goodquality scientific paper! J Obstet Gynecol India. 2018c;68:151-4. https://doi.org/10.1007/s13224-018-1133-5.

5. Khadilkar SS. Rejection blues: why do research papers get rejected? J Obstet Gynecol India. 2018d;68:239-41. https://doi. org/10.1007/s13224-018-1153-1.

6. Khadilkar SS. Scientific misconduct: a global concern. J Obstet Gynecol India. 2018e;68:331-5. https://doi.org/10.1007/s1322 4-018-1175-8.

7. Khadilkar SS. The plague of plagiarism: prevention and cure!!! J Obstet Gynecol India. 2018f;68:425-31. https://doi.org/10.1007/ s13224-018-1182-9.

8. Khadilkar SS. Post-reproductive health: window of opportunity for preventing comorbidities. J Obstet Gynecol India. 2019a;69:15. https://doi.org/10.1007/s13224-019-01202-w.

9. Khadilkar SS. Musculoskeletal disorders and menopause. J Obstet Gynecol India. 2019b;69:99-103. https://doi.org/10.1007/s1322 4-019-01213-7.

10. Khadilkar SS. Obesity in pregnancy: obstetrician' s obstacle. J Obstet Gynecol India. 2019c;69:197-202. https://doi.org/10.1007/ s13224-019-01235-1.

11. Khadilkar SS. Can polycystic ovarian syndrome be cured? unfolding the concept of secondary polycystic ovarian syndrome! J Obstet Gynecol India. 2019d;69:297-302. https://doi.org/10.1007/ s13224-019-01253-z.

12. Khadilkar SS. Thyroid-stimulating hormone values in pregnancy: cutoff controversy continues? J Obstet Gynecol India. 2019e;69:389-94. https://doi.org/10.1007/s13224-019-01272-w.
13. Khadilkar S. Does saving uterus save ovaries? J Obstet Gynecol India. 2020a;70:99-102. https://doi.org/10.1007/s13224-02001308-6.

14. Bhave AA. Coagulopathies in pregnancy: what an obstetrician ought to know! J Obstet Gynecol India. 2019;69:479-82. https:// doi.org/10.1007/s13224-019-01290-8.

15. Khadilkar SV, Khadilkar SS. Bias in clinical practice. J Obstet Gynecol India. 2020;70:1-5. https://doi.org/10.1007/s13224-01901304-5.

16. Purandare $\mathrm{CN}$. Life of an obstetrician and gynaecologist: a 45 years journey. J Obstet Gynecol India. 2020;70:181-3. https:// doi.org/10.1007/s13224-020-01317-5.

17. Khadilkar S. Coping with COVID crisis. J Obstet Gynecol India. 2020b;70:251-5. https://doi.org/10.1007/s13224-020-01358-w.

18. Saraiya UB. The origin of healthcare for women in india: a story of the world of yesterday. J Obstet Gynecol India. 2020;70:323-9. https://doi.org/10.1007/s13224-020-01371-z.

19. Nayak AH, Kapote DS, Fonseca M, et al. Impact of the coronavirus infection in pregnancy: a preliminary study of 141 patients. $J$ Obstet Gynecol India. 2020;70:256-61. https://doi.org/10.1007/ s13224-020-01335-3.

Publisher's Note Springer Nature remains neutral with regard to jurisdictional claims in published maps and institutional affiliations.

\section{About the Author}

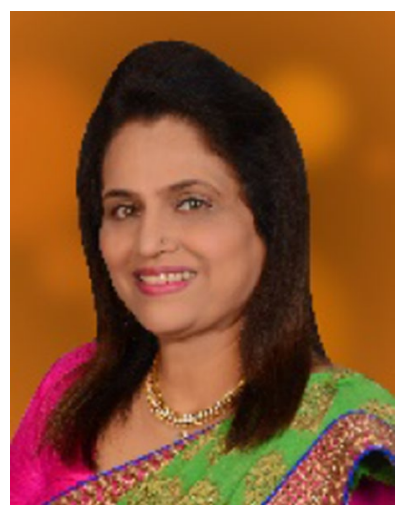

Suvarna Khadilkar is the editor in chief of this journal. She is currently Professor and head of the department of Obstetrics and Gynecology and Consultant Gyne-Endocrinologist, Bombay Hospital Institute of Medical Sciences and Medical Research Centre, Mumbai. In the past, she worked as an Associate Professor and Unit Chief at JJ Group of Hospitals and Grant Medical College [GMC], Mumbai, and thereafter in the capacity of the Professor and Head in Department of Obstetrics and Gynecology, Government Medical College, Kolhapur, Maharashtra. She has over 30 years of teaching experience as an undergraduate and postgraduate teacher and examiner, Mumbai University and Maharashtra University of Health Sciences. Pursuing her interest in endocrinology, she acquired Diploma in Endocrinology from the prestigious University of South Wales, UK, and has been appointed as a recognized teacher in endocrinology in University of South Wales. She is currently the treasurer of FOGSI, Joint secretary of Mumbai Ob-Gyn Society, and National corresponding secretary of Association of Medical Women in India [AMWI]. She has held many prestigious positions like President of Indian Menopause Society, Chairperson of Reproductive Endocrinology Committee of FOGSI, President of AMWI, Mumbai. She has published six textbooks and more than 70 articles at national and international levels. She is recipient of 30 awards for her research work including the Young Scientist Award. 